\title{
Peertechz
}

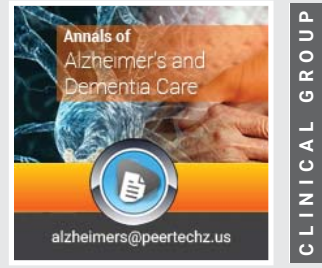

\section{Holistic and individualized interventions for behavioral and psychological symptoms of dementia}

\author{
Naoya Tsukii* \\ Researcher, Research Department, Tokyo Center for Dementia Care Research and Practices, Tokyo, \\ Japan
}

Received: 21 January, 2022

Accepted: 04 February, 2022

Published: 05 February, 2022

*Corresponding author: Naoya Tsukii, MHS, Researcher Research Department, Tokyo Center for Dementia Care Research and Practices, 1 Chome-12-1 Takaido-nishi, Suginami, Tokyo, 168-0071, Japan, Tel: +81-3-3334-2173; E-mail:n.tsukii@dcnet.gr.jp

Keywords: Dementia care; Quality of life; Behavioral and psychological symptoms of dementia; Unmet needs; Living well with dementia

Copyright License: (c) 2022 Tsukii N. This is an open-access article distributed under the terms of the Creative Commons Attribution License, which permits unrestricted use, distribution, and reproduction in any medium, provided the original author and source are credited.

https://www.peertechzpublications.com

\section{Check for updates}

\section{Abstract}

Since "living well with dementia" is a concept that varies from person to person, the care provided is expected to be customized to the individual needs of each person with dementia. Support is expected to involve shared decision-making between people with dementia and their caregivers, and a comprehensive geriatric assessment within the framework of the International Classification of Functioning, Disability, and Health is expected to be conducted to help these persons with dementia realize their goals. Additionally, the Plan-Do-Check-Act cycle is expected to be regularly implemented to verify the effectiveness of the intervention. Although the disability of the individual with dementia increases as the disease progresses, it is important to support them to live positively by reducing their difficulties in daily living.

There is now a trend to encourage the medicalization of care in the name of its scientification. Regarding the management of Behavioral and Psychological Symptoms of Dementia (BPSD) in particular, it is recommended to identify the symptoms and develop a method of care for those symptoms. However, care is provided not for the symptoms but for the persons themselves. This manuscript proposes to reconsider the nature of dementia care as holistic and individualized.

\section{The goals of dementia care}

In the Diagnostic and Statistical Manual of Mental Disorders, $5^{\text {th }}$ Edition (DSM-5), dementia is defined as a progressive, neurodegenerative, and cognitive disorder characterized by a marked decline in cognitive function from previous levels and impaired independence in daily living [1]. In dementia, a decline in cognitive function makes it difficult to undertake social interactions smoothly. For example, symptoms of memory impairment may include the inability to recall appointments, schedules, or previous conversations. These symptoms can interfere with the social lives of individuals with dementia. Therefore, a person with dementia requires support from others; in this regard, it is recommendable to have a good relationship with their caregivers.

One of the basic concepts of dementia care is that it is person-centered and emphasizes the relationship between the person with dementia and their caregiver [2]. Person-centered care ensures that the needs, preferences, and values of the person with dementia guide the clinical decision-making and that care is provided in a respectful and responsive manner [2]. In other words, dementia care is about supporting a person with dementia to "live better". However, such support does not mean that the well-being of the caregiver is sacrificed. "Living well" may have different meanings for each individual, and this diversity is expected to be respected. Therefore, caregivers are expected to provide customized support for people with dementia according to the disease progression. Further, positive interaction between persons with dementia and their caregivers is desirable in order to improve the Quality of Life (QOL) of both parties [3]. If dementia care is not beneficial to persons with dementia and their caregivers, in the long run, it 
can lead to the deterioration of relationships and increase the burden of care for caregivers.

To live well every day with dementia, it is desirable that persons with dementia share the decision-making process with caregivers on providing support to protect their dignity and to stabilize the relationships with those around them. After the onset of dementia, even family members may find it difficult to communicate with the person with dementia. It has been reported that sharing hobbies can help stabilize the relationship between persons with dementia and family members, reduce the BPSD, shorten the families' care time, and improve the care skills of the family members [4,5].

In addition to the ethical and emotional aspects of empathy, caregivers are expected to have significant cognitive empathy skills, which is the ability to understand the perspective of the person with dementia [6]. Cognitive empathy is important in dementia care, especially considering the factors behind the behaviors associated with cognitive decline, which make it difficult for people with dementia to communicate effectively.

\section{Behavioral and psychological symptoms of dementia}

BPSD is defined by the International Psychogeriatric Association (IPA) as a symptom of disturbances in perception, thought content, mood, or behavior that frequently occur in persons with dementia [7]. The specific BPSD includes psychological symptoms such as delusions, misperceptions, hallucinations, depression, and anxiety, as well as aggressive behavior, wandering, restlessness, and agitation [7]. BPSD is experienced by most people with dementia [8-10]. Caregivers often view BPSD as problematic behavior but they can be considered a sign that the needs of the person with dementia are not being met, including physical and psychological conditions, social interactions, and economic status (Figure 1). The emergence of BPSD has been associated with increased caregiver burden [11-14], decreased QOL of caregivers and persons with dementia [13,14], and caregiver burnout [15].

In medical practice, the goal of the interventions for BPSD is mainly their reduction, while in dementia care, attempts

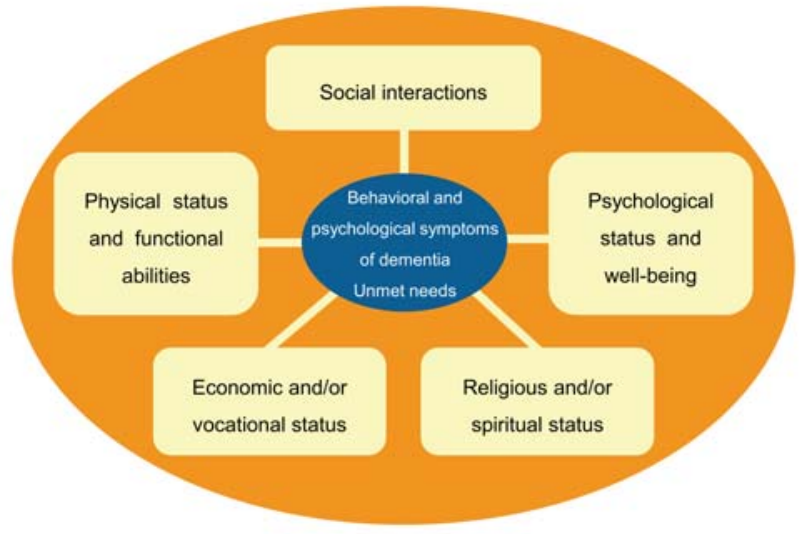

Figure 1: Elements of unmet needs.

Unmet needs in all aspects, including physical and psychological conditions, social interactions, and economic status, manifest as behavioral and psychological symptoms of dementia. are being made to recognize BPSD from the perspective of the person with dementia (except those caused by brain degeneration, such as the association between behavioral disorders and frontal lobes in frontotemporal dementia [16] and the association between visual hallucinations and frontal and occipital lobe functions in dementia with Lewy bodies [17]). As has been emphasized earlier, highly experienced caregivers are capable to exercise cognitive empathy to try to ensure that the normal human needs of persons with dementia are met, including undertaking meaningful activities, emotional satisfaction, and social communication [18]. Meeting the BPSD needs of persons with dementia will also lead to improved QOL $[19,20]$, indicating that BPSD and QOL are inextricably linked [21]. Caregivers are required to provide holistic care rather than focus on a single BPSD symptom. It can be inferred that meeting the needs of people with dementia through holistic care will lead to "living well with dementia".

Implications of assessing behavioral and psychological symptoms of dementia indicators in dementia care

There are three purposes for using BPSD assessment indicators for caregivers and health care professionals. The first is to identify obstacles to living better. Caregivers may identify the needs of a person with dementia by examining the person's words and nonverbal expressions, including facial expressions, gestures, voice, and behavior. However, this requires that caregivers have specific skills. Otherwise, caregivers can use the BPSD assessment index as a tool to evaluate the needs of the person with dementia that they have not noticed before. Second, the assessment can serve as a communication support tool to analyze the background factors that cause BPSD and to discuss how to cope with the problem among the team of formal caregivers. Third, it can be an opportunity for caregivers to reflect on their care and how it affects the improvement or worsening of symptoms.

Although assessing BPSD is useful for professional caregivers, it is not enough to assess BPSD alone; assessment from a comprehensive perspective is desirable. Therefore, Comprehensive Geriatric Assessment (CGA) [22] is useful for the holistic care of people with dementia (Figure 2).

\section{Tailor-made dementia care}

In dementia care, holistic, individualized interventions are desirable, whereas, in usual medical practice, the evidencebased standard treatment is recommended for an identified symptom.

However, even in usual medical practice, physicians and medical professionals do not paternalistically decide and implement treatment regardless of the person's will. The physicians and medical professionals are expected to provide information based on evidence, share the information with the person, respect the person's will, and decide the treatment policy with a Shared Decision-Making (SDM) approach [23]. In dementia care, respecting the will of the person with dementia is even more important. Since dementia care is desirable to be an intervention centered on and tailored to the person

Citation: Tsukii N (2022) Holistic and individualized interventions for behavioral and psychological symptoms of dementia. Ann Alzheimers Dement Care 6(1): 014- 
with dementia, it is desirable to undertake an SDM approach by including people with dementia, those close to them, and healthcare professionals, while respecting the person with dementia's values and wishes and taking into consideration the current situation, balance of benefits and harms of the prescribed treatment, and other information.

Figure 3 depicts an SDM chart in the provision of dementia care by professional caregivers: the first step is to determine the goals of care together with the person with dementia through communication tailored to the person's cognitive function. Next, the caregiver is expected to analyze the overall policy of care within the framework of the World Health Organization International Classification of Functioning, Disability, and Health (ICF) [24]: applying the CGA assessment to the ICF framework to form a holistic image of the person with dementia (Figure 4). Furthermore, care staff is expected to practice the Plan-Do-Check-Act (PDCA) cycle [25], a method of continuous improvement. In other words, they are expected to comprehensively evaluate the person with dementia using CGA, plan the care (Plan), practice the care (Do), check the effectiveness (Check), formulate improvements and countermeasures (Act), and develop new care plans (Plan) (Figure 3).

The composition of this tailor-made intervention is expected to be holistic, including maintaining residual abilities, psychological aspects, and a supportive environment, including family support [26]. In addition, as dementia progresses, the disability of the person with dementia increases, and the needs of people with dementia change depending on the disease progression as well as on their physical and psychological condition. Hence, it is necessary to provide care that meets the needs of the persons with dementia according to their situation and progression of dementia.

\section{Asking persons with dementia what makes them happy}

As mentioned above, BPSD and QOL are inextricably linked [21] and care for BPSD aims at meeting the unmet needs of

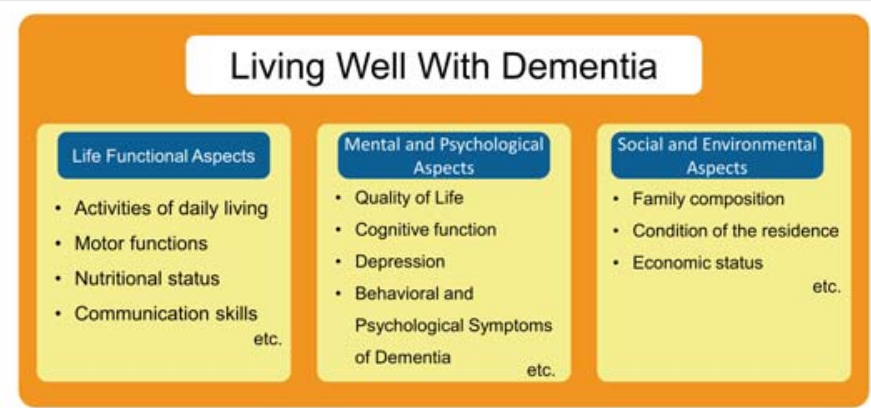

Figure 2: Comprehensive assessment for "living well with dementia" (based on reference [21]).

It is important for caregivers to provide individualized support to people with dementia since their backgrounds differ greatly from person to person. To live well with dementia, caregivers must plan care from a comprehensive perspective; otherwise, it will be difficult to meet the needs of the person with dementia. Therefore, caregivers need to grasp the whole picture by conducting a comprehensive assessment, such as the comprehensive geriatric assessment (CGA)

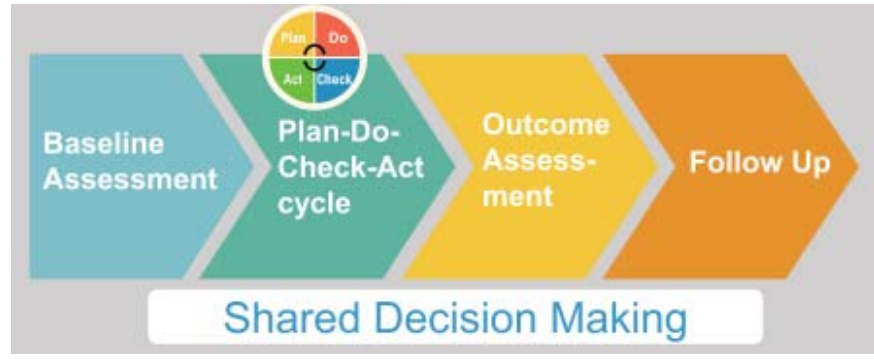

Figure 3: Process of the dementia care model.

In dementia care, shared decision-making between the person with dementia and the caregiver is carried out at every step of the process. The first step is to determine the goals of care for people with dementia and their caregivers. Caregivers analyze current issues and conduct assessments within the framework of the International Classification of Functioning, Disability, and Health. The caregiver matches the results of these assessments and repeats the Plan-Do-Check-Act process for continuous improvement.

persons with dementia. Therefore, it may be desirable to go one step further and more proactively ask the person with dementia directly "What makes you happy?" [27-29]. What makes a person with dementia happy (the overall goal of life) varies from one individual to another. Therefore, caregivers are desirable to support people with dementia according to their wishes considering their perspective.

\section{Limitations}

This manuscript is the view of the author, who will continue to accumulate evidence in line with this view. As mentioned in the introduction, this manuscript proposes to reconsider dementia care as a holistic and individualized approach. To this end, it may be required to demonstrate the unique value of this model of care, rather than medicalizing it, by presenting evidence of its advantages in comparison with the conventional medical framework of identifying symptoms and verifying the effects of the prescribed interventions [30].

\section{Conclusion}

Dementia care is about "living well with dementia," and since what makes a person with dementia feel happy varies from person to person, tailored interventions are desirable. Dementia care aims to create a relationship of mutual coexistence and reciprocity in which the person with dementia is grateful for the support ofothers and does what he or she can to help others. Even though the number of things that a person with dementia cannot do increases as the disease progresses, it is important to support that person is looking for things that they can do and live positively while receiving support from others.

\section{Acknowledgment}

The author is grateful to persons with dementia who are a source of inspiration, and Dr. Maki for supervising the manuscript.

\section{Funding}

This study was supported by Grants-in-Aid for Scientific Research (\# 19K11432).

Citation: Tsukii N (2022) Holistic and individualized interventions for behavioral and psychological symptoms of dementia. Ann Alzheimers Dement Care 6(1): 014- 

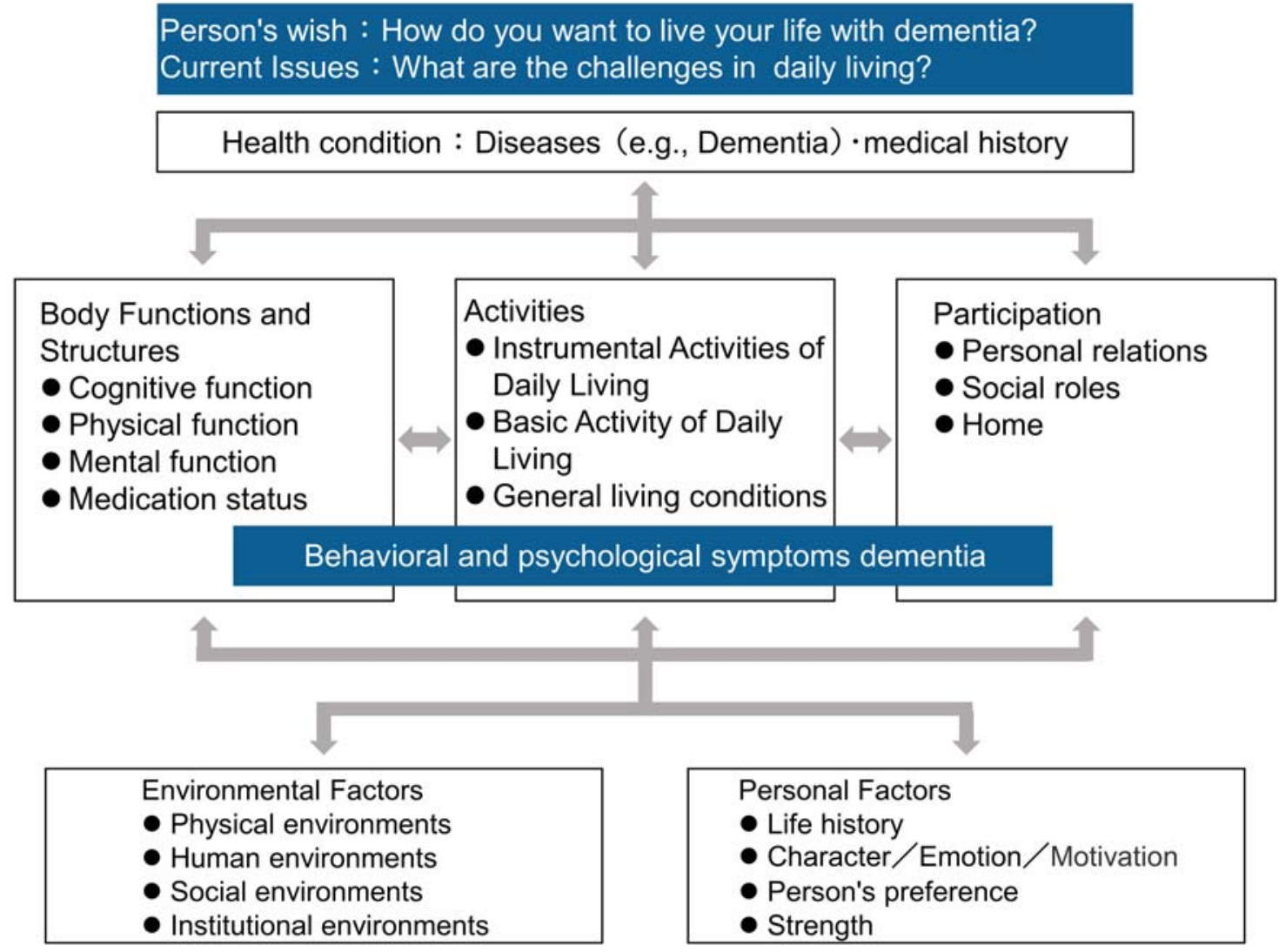

Figure 4: Organizing our understanding of dementia based on the International Classification of Functioning, Disability, and Health.

The International Classification of Functioning, Disability, and Health classifies functioning from a holistic perspective, shifting from the International Classification of Impairments, Disabilities, and Handicaps [24], which focuses on individual diseases and disabilities.

It shows the perspective of the quality of life of the person with dementia and their life as a whole. Next, caregivers will identify body functions and structures, activities, participation, environmental factors, and personal factors to solve the current issues. Behavioral and psychological symptoms of dementia (BPSD) are characteristic of dementia and are classified differently according to symptoms. Symptoms of brain degeneration are considered to belong to the "Body Functions and Structures" category (e.g., optical illusions). Some behavioral symptoms belong to "Activities" (e.g., wandering) and others to "Participation" (e.g., violence and verbal abuse). BPSD may be influenced by environmental factors and physical conditions (e.g., pain, sleep, constipation, dehydration), which may result in increased symptoms.

\section{References}

1. American Psychiatric Association (2013) Diagnostic and Statistical Manual of Mental Disorders: DSM-5. Amer Psychiatric.

2. Kitwood T (1997) Dementia Reconsidered: The Person Comes First (Rethinking Ageing Series). Open University Press. Link: https://bit.ly/34eQlkj

3. Maki Y, Sakurai T, Toba K (2018) A new model of care for patients with dementia: the Japanese initiative for dementia care. In: Michel JP, Beattie BL, Martin FC, Walston JD, editors. Oxford textbook of geriatric medicine. 3rd ed Oxford: Oxford University Press. 1027-1032. Link: https://bit.ly/3AV1nqS

4. Gitlin LN, Winter L, Burke J, Chernett N, Dennis MP, et al. (2008) Tailored activities to manage neuropsychiatric behaviors in persons with dementia and reduce caregiver burden: a randomized pilot study. Am J Geriatr Psychiatry 16 229-239. Link: https://bit.ly/3Goh5vG

5. Gitlin LN, Mann WC, Vogel WB, Arthur PB (2013) A non-pharmacologic approach to address challenging behaviors of Veterans with dementia: description of the tailored activity program-VA randomized trial. BMC Geriatr 13: 96. Link: https://bit.ly/34rv86u

6. Decety J, Yoder KJ (2016) Empathy and motivation for justice: cognitive empathy and concern, but not emotional empathy, predict sensitivity to injustice for others. Soc Neurosci 11: 1-14. Link: https://bit.ly/3GhUfG8

7. Finkel SI, Brodaty H, Draper B (1999) BPSD Consensus Statement. International Psychogeriatric Association. Link: https://bit.ly/3gnWEVf
8. Cerejeira J, Lagarto L, Mukaetova-Ladinska FB (2012) Behaviora and psychological symptoms of dementia. Front Neurol 3: 73. Link: https://bit.ly/3Lacwsr

9. Scales K, Zimmerman S, Miller SJ (2018) Evidence-Based Nonpharmacological Practices to Address Behavioral and Psychological Symptoms of Dementia. Gerontologist 58: S88-S102. Link: https://bit.ly/3LhuBVM

10. Steinberg M, Shao H, Zandi P, Lyketsos CG, Welsh-Bohmer KA, et al. (2008) Point and 5-year period prevalence of neuropsychiatric symptoms in dementia: the Cache County Study. Int J Geriatr Psychiatry 23: 170-177. Link: https://bit.ly/3gi8EHK

11. Baharudin AD, Din NC, Subramaniam P, Razali R (2019) The associations between behavioral-psychological symptoms of dementia (BPSD) and coping strategy, burden of care and personality style among low-income caregivers of patients with dementia. BMC Public Health 19: 447. Link: https://bit.ly/3on31fJ

12. Terum TM, Andersen JR, Rongve A, Aarsland D, Svendsboe EJ, et al. (2017) The relationship of specific items on the Neuropsychiatric Inventory to caregiver burden in dementia: a systematic review. Int J Geriatr Psychiatry 32 703-717. Link: https://bit.ly/3Lakzps

13. Feast A, Moniz-Cook E, Stoner C, Charlesworth G, Orrell M (2016) A systematic review of the relationship between behavioral and psychological symptoms (BPSD) and caregiver well-being. Int Psychogeriatr 28: 1761-1774. Link: https://bit.ly/3Gq9M6T

Citation: Tsukii N (2022) Holistic and individualized interventions for behavioral and psychological symptoms of dementia. Ann Alzheimers Dement Care 6(1): 014- 
14. Feast A, Orrell M, Charlesworth G, Melunsky N, Poland F, et al. (2016) Behavioural and psychological symptoms in dementia and the challenges for family carers: systematic review. $\mathrm{Br} J$ Psychiatry 208: 429-434. Link: https://bit.ly/3AUBzes

15. Hiyoshi-Taniguchi K, Becker CB, Kinoshita A (2018) What Behavioral and Psychological Symptoms of Dementia Affect Caregiver Burnout? Clin Gerontol 41: 249-254. Link: https://bit.ly/3Hqxj90

16. Agosta F, Canu E, Sarro L, Comi G, Filippi M (2012) Neuroimaging findings in frontotemporal lobar degeneration spectrum of disorders. Cortex 48: 389-413. Link: https://bit.ly/34pZarf

17. Pezzoli S, Cagnin A, Bandmann O, Venneri A (2017) Structural and Functional Neuroimaging of Visual Hallucinations in Lewy Body Disease: A Systematic Literature Review. Brain Sci 7: 84. Link: https://bit.ly/3ghbkFH

18. Cohen-Mansfield J, Dakheel-Ali M, Marx MS, Thein K, Regier NG (2015) Which unmet needs contribute to behavior problems in persons with advanced dementia? Psychiatry Res 228: 59-64. Link: https://bit.ly/3AUAi73

19. Black BS, Johnston D, Morrison A, Rabins PV, Lyketsos CG, et al. (2012) Quality of life of community-residing persons with dementia based on selfrated and caregiver-rated measures. Qual Life Res 21: 1379-1389. Link: https://bit.ly/3sdpsVT

20. Black BS, Johnston D, Leoutsakos J, Reuland M, Kelly J, et al. (2019) Unmet needs in community-living persons with dementia are common, often nonmedical and related to patient and caregiver characteristics. Int Psychogeriatr 31: 1643-1654. Link: https://bit.ly/3unCfb9

21. Spilker B (1996) Quality of life and pharmacoeconomics in clinical trials, 2nd edn.: Lippincott-Raven. Link: https://bit.ly/3L5fZZm

22. Solomon D, Sue Brown A, Brummel-Smith K, Burgess L, D'Agostino RB, et al. (2003) Best paper of the 1980s: National Institutes of Health Consensus Development Conference Statement: geriatric assessment methods for clinical decision-making. 1988. J Am Geriatr Soc 51: 1490-1494. Link: https://bit.ly/32Ts9Do

23. Elwyn G, Laitner S, Coulter A, Walker E, Watson P, et al. (2010) Implementing shared decision making in the NHS. BMJ 341: c5146. Link: https://bit.ly/35LNRKK

24. World Health Organization (2021) International Classification of Functioning Disability and Health. Link: https://bit.ly/35NFTRI

25. Ministry of Health, Labour and Welfare. About Long-term care Information system For Evidence. Link: https://bit.ly/35BuQKM

26. Maki Y, Sakurai T, Okochi J, Yamaguchi H, Toba K (2018) Rehabilitation to live better with dementia. Geriatr Gerontol Int 18: 1529-1536. Link: https://bit.ly/3IWPWBO

27. Maki Y (2019) Proposal for the empowerment of interdependent selfmanagement support for people with dementia. Journal of Geriatric Care and Research 6: 3-8. Link: https://bit.ly/3L8zKza

28. Maki Y (2021) Ikigai interventions for primary, secondary, and tertiary prevention of dementia. Aging and Health Research 1: 10026. Link: https://bit.ly/3Hpeq6d

29. Maki Y (2021) Self-prevention and self-management of the behavioral and psychological symptoms of dementia: A case study. Ann Alzheimers Dement Care 5: 11-19. Link: https://bit.ly/3J1anxm

30. Maki Y (2018) A reappraisal of the evidence of non-pharmacological intervention for people with dementia. Journal of Geriatric Care and Research 5: 41-42. Link: https://bit.ly/3sbZ4f2

\section{Discover a bigger Impact and Visibility of your article publication with}

\section{Peertechz Publications}

\section{Highlights}

* Signatory publisher of ORCID

* Signatory Publisher of DORA (San Francisco Declaration on Research Assessment)

* Articles archived in worlds' renowned service providers such as Portico, CNKI, AGRIS, TDNet, Base (Bielefeld University Library), CrossRef, Scilit, J-Gate etc.

* Journals indexed in ICMJE, SHERPA/ROMEO, Google Scholar etc.

* OAI-PMH (Open Archives Initiative Protocol for Metadata Harvesting)

* Dedicated Editorial Board for every journa

* Accurate and rapid peer-review process

* Increased citations of published articles through promotions

- Reduced timeline for article publication

Submit your articles and experience a new surge in publication services (https://www.peertechz.com/submission). 